\title{
Gun use in the United States: results from two national surveys
}

\author{
D Hemenway, D Azrael, M Miller
}

\begin{abstract}
Objectives-To determine the relative incidence of gun victimization versus self defense gun use by civilians in the United States, and the circumstances and probable legality of the self defense uses. Methods-National random digit dial telephone surveys of the adult population were conducted in 1996 and 1999. The Harvard surveys appear unique among private surveys in two respects: asking (1) open ended questions about defensive gun use incidents and (2) detailed questions about both gun victimization and self defense gun use. Five criminal court judges were asked to assess whether the self reported defensive gun uses were likely to have been legal.

Results-Even after excluding many reported firearm victimizations, far more survey respondents report having been threatened or intimidated with a gun than having used a gun to protect themselves. A majority of the reported self defense gun uses were rated as probably illegal by a majority of judges. This was so even under the assumption that the respondent had a permit to own and carry the gun, and that the respondent had described the event honestly.

Conclusions-Guns are used to threaten and intimidate far more often than they are used in self defense. Most self reported self defense gun uses may well be illegal and against the interests of society.

(Injury Prevention 2000;6:263-267)
\end{abstract}

Keywords: firearms; guns; self defense; legality

The United States has a higher homicide rate than other developed nations, and most of our murders are committed with firearms. On an average day in the 1990s in the United States, 35-50 Americans were murdered with firearms, and another 120-160 were shot in assaults but did not die. ${ }^{1}$ Shootings that result in injury are a small percentage of hostile events involving firearms. ${ }^{2}$ In some of these events guns may thwart criminal assaults, in others they may be instruments of aggression.

Evidence about the incidence and characteristics of gun victimization and self defense gun use come from two types of survey. The first is the large, public National Crime Victimization Survey (NCVS). The NCVS, conducted by the Census Bureau for the Bureau of Justice Statistics, asks questions of the same household every six months for three years. By excluding Professor Hemenway

(hemenway@hsph.harvard.edu) incidents reported in the first interview (that is, by "bounding" the responses), the NCVS greatly reduces the substantial problem of "telescoping" (the reporting of events that actually occurred outside the time frame in question). In criminal victimization surveys, telescoping can increase estimates by between $40 \%$ and $50 \%$ depending on the type of crime; the inflation rate is greatest for violent crimes. ${ }^{3}$

The NCVS focuses on six specific serious crimes (for example, assault, rape, robbery) and asks the respondent whether s/he has been the victim of an attempted or completed crime within the preceding six months. Follow up questions ask whether the offender used a gun in the criminal attempt, as well as what, if anything, the respondent did to protect him/ herself. Estimates from the NCVS suggest that each year about one million violent crimes involve guns while victims use guns in self defense perhaps 60000 to 120000 times. $^{56}$

Many smaller, one shot private surveys have asked one or more questions about self defense gun use. ${ }^{7}$ Estimates of self defense gun use from such surveys are an order of magnitude higher than the NCVS estimates. Two features of these private surveys probably explain most of this difference: (1) responses are unbounded and (2) all respondents are asked about defensive gun use, not just those respondents who report that they have been the victim of an attempted crime..$^{8-11}$ These two features should also make private survey estimates of gun victimization higher than the NCVS estimates. ${ }^{2}$

In 1996 and 1999 national surveys focusing on defensive and offensive gun use were conducted under the auspices of the Harvard Injury Control Research Center. The Harvard surveys appear to be the only private surveys to ask either (1) open ended questions about defensive gun uses, or (2) detailed questions of each respondent about both gun victimization and self defense gun uses. This article presents evidence on the relative frequency and circumstances of these two types of gun use, as well as on their probable legality.

\section{Methods}

Data come from two national random digit dial surveys conducted by Fact Finders, Inc in the spring of 1996 and the spring of 1999. The samples comprise, respectively, 1905 and 2521 adults living in the 50 states.

The samples were stratified by state, with the number of interviews designated for each state determined by that state's population relative to the total population according to the 1990 census. All households with a single telephone line, including those with unlisted numbers, had an equal probability of inclusion in the 
sample. Households without a telephone were excluded from the sample.

No more than one adult from each household was interviewed. Rather than interview the adult who happened to be at home at the time of the call, the interviewers alternately asked to speak with a man or with a woman living in the household. If there was no adult living in the household of the requested gender, the initial respondent was interviewed. Results show unweighted data.

Once a telephone number was randomly selected, as many as 10 repeat phone calls were made until a final disposition was assigned. In $1996,27 \%$ of contacted households refused to participate in the survey; in 1999, 35\% refused. These response rates are comparable to other self defense gun use surveys. ${ }^{11}{ }^{12}$

Respondents who answered yes to either gun use qualifying question were asked up to 30 follow up questions about the most recent event, including an open ended question which asked them to describe the incident. All results eliminate respondents who were police officers, security guards, or military personnel. Results also eliminate cases in which the respondent reported that the event occurred more than five years before the survey or outside the United States.

In the case of hostile gun displays, we also eliminated incidents in which the respondent refused to provide any detailed information about the event at the time of the initial interview, the respondent appeared to be an observer rather a participant in the event, or was thought to be a criminal (for example, by the police). We were more stringent about what was counted as a hostile gun display, and more permissive about was counted as a self defense gun use.

The specific qualifying questions in both surveys were similar. ${ }^{13}$ In 1999 respondents were asked "In the past five years, has anyone used, displayed or brought out a gun in a hostile manner against you [italics added], even if this event did not take place as part of the commission of a crime?" The 1996 question did not include the "against you" and so obtained more instances when the respondent was merely a witness.

The 1999 survey inadvertently omitted an open ended question about the most recent hostile gun display. Four to eight months after the initial interview we tried to recontact all those who had reported a hostile gun display against them. We were able to gain a verbatim description of the most recent event from half these respondents. In $6 \%$ of these instances it appeared that the respondent merely witnessed the hostile gun display. In calculating the number of hostile gun displays, we thus excluded $6 \%$ of all non-contacted respondents who reported a hostile gun display.

All respondents in the 1999 survey were asked "In the past five years, have you used, displayed or brought out a gun in self defense to protect yourself from a person or people?" The 1996 survey asked "In the past five years, have you used a gun to protect yourself from a person or people?"

In order to obtain a generous estimate of self defense gun uses, we included incidents even when the respondent refused to give any information about the event or, from the description, it appeared the other party never knew the respondent displayed the gun.

Self defense gun use incidents were summarized and sent to five criminal court judges (from California, Pennsylvania, and Massachusetts) who were assured anonymity. The judges were told to assume that the respondent had a permit to own and carry the gun and had described the event honestly from his/her own perspective. The judges were then asked to give their best guess whether, based on the respondent's description of the incident, the respondent's use of the gun was very likely legal, likely legal, as likely as not legal, unlikely legal, or very unlikely legal.

\section{Results}

The percentages of respondents reporting hostile gun displays in the two surveys are not statistically different, nor are the percentages of respondents reporting a self defense gun use. Results of the two surveys are therefore combined in the analysis.

\section{HOSTILE GUN DISPLAYS}

On the 1996 survey, 122 respondents reported a hostile gun display against them. We eliminated over half of these for a variety of reasons (table 1), leaving 58 civilians who

Table 1 Hostile gun displays: gun use against respondents

\begin{tabular}{|c|c|c|c|c|c|c|}
\hline & \multicolumn{2}{|c|}{$1996(n=1905)$} & \multicolumn{2}{|c|}{$1999(n=2521)$} & \multicolumn{2}{|l|}{ Combined } \\
\hline & Respondents & Incidents & Respondents & Incidents & Respondents & Incidents \\
\hline Total positives & 122 & 450 & 131 & 342 & 253 & 792 \\
\hline \multicolumn{7}{|l|}{ Exclusions: } \\
\hline Witness only & 31 & 112 & $6^{\star}$ & $12^{\star}$ & 37 & 124 \\
\hline Thought to be criminal & 8 & 16 & 14 & 35 & 22 & 51 \\
\hline Police officer & 10 & 150 & 11 & 30 & 21 & 180 \\
\hline Security guard & 2 & 3 & 2 & 4 & 4 & 7 \\
\hline Military personnel & 3 & 6 & 2 & 1 & 5 & 7 \\
\hline Arson investigator & 1 & 2 & 0 & 0 & 1 & 2 \\
\hline Private investigator & 1 & 25 & 0 & 0 & 1 & 25 \\
\hline Outside of US & 2 & 3 & 0 & 0 & 2 & 3 \\
\hline Out of time frame ( $>5$ years) & 1 & 1 & 1 & 4 & 2 & 5 \\
\hline Insufficient information & 3 & 16 & 0 & 0 & 3 & 16 \\
\hline Other & 2 & 4 & 1 & 97 & 3 & 101 \\
\hline Total exclusions & 64 & 338 & 37 & 183 & 101 & 521 \\
\hline Cases & 58 & 112 & 94 & 159 & 152 & 271 \\
\hline
\end{tabular}

${ }^{\star}$ Based on $\%$ of a sample of cases in which the narrative indicated that respondent had only witnessed the event. 
reported 112 hostile gun displays against them in the previous five years. ${ }^{2}$

On the 1999 survey, 131 respondents reported a hostile gun uses against them. One man reported 97 gun uses and was excluded. We also excluded 15 police, security guards and military personnel, 14 people who responded that the gun user might have thought $\mathrm{s} /$ he was a criminal, and one who reported that the event took place six years before the survey. Of the remaining 100 , we received a verbatim description from $50 ; 6 \%$ appeared to have merely witnessed the event ("It was between two other people; a gun was displayed, it could have ricocheted"). We eliminated $6 \%$ of the 100, leaving 94 respondents who reported 159 events.

After appropriate exclusions, 152 respondents from the combined surveys reported 271 incidents (table 1 ).

Three examples of hostile gun displays against respondents from the 1999 survey are:

- "I'm a cattle farmer and he's a cattle farmer. He was putting his bulls and heifers up near the fence and my bull broke out and he got mad".

- "I was on a date. He pulled the gun when I mentioned breaking up with him".

- "I was mugged in New York".

SELF DEFENSE GUN USE

On the 1996 survey, 14 civilian respondents reported using a gun in self defense in the past five years, accounting for 54 incidents. On the 1999 survey, 29 civilian respondents reported using a gun in self defense, accounting for 92 gun uses. For both surveys combined, a total of 146 self defense gun uses were reported by 43 people who were not police, military personnel, or security guards (table 2 ).

In each survey, the number of respondents reporting that they were gun victims exceeded the number of respondents reporting that they had used a gun in self defense by over three to one, 152 to $43(\mathrm{p}<0.001)$ overall.

On both surveys combined, $2.9 \%$ of gun owners, $0.3 \%$ of those living in the home with someone who owns a gun, and $0.4 \%$ of non-gun owners reported a self defense gun use (table 3). After eliminating police, security guards and military personnel, approximately $1 \%$ of respondents reported a self defense gun use (43/4378).

Of the 43 respondents reporting a self defense gun use, six did not provide a description of the most recent event, and for two more the descriptions indicated that the respondent did not use the firearm (for example, one never encountered the thieves who had stolen his truck). The criminal court judges were shown summaries of the remaining 35 events; each judge rated each event. Twenty per cent of the time a judge rated a case as "as likely legal as illegal". Excluding these ratings (when judges often said there was not enough information), a majority of the judges rated 18 of the $35(51 \%)$ as probably illegal and 15 of the $35(43 \%)$ as probably legal. For two there was no majority opinion. In 23 of 35 events the judges were unanimous in their ratings; nine times there was one dissenter; and in three instances the ratings were either $3-2$ or $2-2$ in terms of the probable legality of the self defense gun use.

Two examples from the 1999 survey of incidents that were unanimously deemed probably illegal were:

- A 62 year old male said that at 6 pm "the police called. My alarm at my business went off so I went there to shut it off. Two men were outside my building, so from my car I shot at the ground near them". The respondent said the men were trespassing.

- A 58 year old male was inside his home at 2 pm. "I was watching a movie and [an acquaintance] interrupted me. I yelled that I was going to shoot him and he ran to his car". The respondent said his acquaintance was committing a verbal assault. The respondent's gun, a .44 Magnum, was located "in my holster on me".

Two examples of self defense gun use from the 1999 survey that were unanimously deemed probably legal were:

- A 26 year old male was with friends at another's home. At 8:30 am "a friend of mine was in the process of getting robbed and he was drunk. We went to help him just as the robbers were leaving". The respondent's gun was not loaded and "I never really took it out of my pocket".

- A 38 year old male was inside his home at 4 am. "Someone broke in; I woke up to the sound. I got my gun from the safe [loaded it] and went downstairs. The person left and I called the police". The respondent did not know whether the burglar had a weapon.

Over two thirds $(68 \%)$ of the 146 self defense gun use incidents from the two surveys were reported by six respondents. Three people claimed 50, 20 and 15 self defense incidents in the previous five years, but refused to describe the most recent event. In the 1999 survey, an 18 year old male reported six cases. He described the most recent incident: "I was at

Table 2 Self defense gun use by respondents

\begin{tabular}{|c|c|c|c|c|c|c|}
\hline & \multicolumn{2}{|c|}{$1996(n=1905)$} & \multicolumn{2}{|c|}{$1999(n=2521)$} & \multicolumn{2}{|l|}{ Combined } \\
\hline & Respondents & Incidents & Respondents & Incidents & Respondents & Incidents \\
\hline Total positives & 23 & 222 & 47 & 445 & 70 & 667 \\
\hline \multicolumn{7}{|l|}{ Exclusions: } \\
\hline Police officer & 6 & 161 & 15 & 254 & 21 & 415 \\
\hline Security guard & 0 & 0 & 1 & 2 & 1 & 2 \\
\hline Military personnel & 2 & 6 & 2 & 97 & 4 & 103 \\
\hline Out of time frame ( $>5$ years) & 1 & 1 & 0 & 0 & 1 & 1 \\
\hline Total exclusions & 9 & 168 & 18 & 353 & 27 & 521 \\
\hline Cases & 14 & 54 & 29 & 92 & 43 & 146 \\
\hline
\end{tabular}


Table 3 Number (\%) of individuals reporting a self defense gun use by reported gun ownership

\begin{tabular}{|c|c|c|c|c|c|c|c|c|c|}
\hline \multirow[b]{2}{*}{ Firearm } & \multicolumn{3}{|l|}{1996} & \multicolumn{3}{|l|}{1999} & \multicolumn{3}{|l|}{ Combined } \\
\hline & $\begin{array}{l}\text { Defensive } \\
\text { use }\end{array}$ & Total & $\%$ & $\begin{array}{l}\text { Defensive } \\
\text { use }\end{array}$ & Total & $\%$ & $\begin{array}{l}\text { Defensive } \\
\text { use }\end{array}$ & Total & $\%$ \\
\hline Personally own gun & 9 & 457 & 2.0 & 22 & 618 & 3.6 & 31 & 1075 & 2.9 \\
\hline Gun in household & 1 & 307 & 0.3 & 1 & 417 & 0.2 & 2 & 724 & 0.3 \\
\hline Household without gun & 4 & 1085 & 0.4 & 6 & 1462 & 0.4 & 10 & 2547 & 0.4 \\
\hline Refuse & 0 & 30 & 0.0 & 0 & 2 & 0.0 & 0 & 32 & 0.0 \\
\hline Excluded & - & 26 & - & - & 22 & - & - & 48 & - \\
\hline Total & 14 & 1905 & 0.7 & 29 & 2521 & 1.2 & 43 & 4469 & 1.0 \\
\hline
\end{tabular}

school and they pulled a gun during an argument. They fired and I fired".

\section{Discussion}

Consistent with results from the NCVS and private one shot surveys, ${ }^{2}$ we find that far more respondents report criminal gun uses against them than self defense gun uses by them. The results hold even though, in order to be as conservative as possible, we (1) eliminate many of the reported hostile gun uses against the respondent, and (2) include virtually all the reported self defense gun uses.

Our surveys yield higher estimates of both criminal and self defense gun use than does the NCVS, probably due to telescoping and due to the fact that our respondents could report a gun use without first reporting that someone tried to commit a crime against them. ${ }^{811}$ These factors need not differentially affect the relative incidence of gun victimization versus self defense gun use, which we report here.

However, our results should not be extrapolated to obtain population based estimates of the absolute number of gun uses. If we have as little as $1 \%$ random misclassification, our results could be off by orders of magnitude. It appears we can obtain substantially higher rates of self defense gun use if we ask respondents about events in the previous six months rather than the previous five years. ${ }^{7}$ On the other hand, we can obtain substantially lower rates of self defense gun use if we eliminate the handful of respondents who report the vast majority of uses, the various respondents who report uses that do not appear to meet reasonable criteria for actual use, or the respondents whose use appears offensive rather than defensive.

While it is sometimes presumed that self defense gun use is beneficial for society, that notion has been viewed with increasing skepticism. $^{10}{ }^{11}$ It is noteworthy that in prison surveys, about half of convicted felons who have fired a gun claim to have done so in self defense. ${ }^{14}$

In our survey, the criminal court judges who rated the incidents determined that at least half were probably illegal - even after assuming that the respondent had a permit to own and carry a gun and described the incident honestly. We expect that the true percentage of reported self defense gun uses that are illegal is higher than $50 \%$ for at least two reasons.

First, three respondents reported over 58\% of the self defense gun uses, and none of their accounts were read by the judges (since all refused to provide a description of the most recent event). Many reported self defense gun uses from a respondent creates a suspicion that the uses may be aggressive rather than defensive.

Second, the reports read by the judges are only one side of a hostile interaction that usually occurred months or years before the survey. We expect respondents will view the hostile encounter from their own perspective; in any mutual combat both participants may believe that the other side is the aggressor and that they themselves are acting in self defense. In addition, when describing the event, respondents will typically want to present themselves in the best possible light. ${ }^{15-20}$

Certainly some self defense gun uses are legal and in the public interest. But many are not. The possibility of using a gun in a socially useful manner-against a criminal during the commission of a crime-will rarely, if ever, occur for the average gun owner. By contrast, at any other moment, the use of a gun against another human is illegal, and socially undesirable. Regular citizens with guns, who are sometimes tired, angry, drunk or afraid, and who are not trained in dispute resolution or on when it is proper to use a firearm, have many opportunities for inappropriate gun use. People engage in innumerable annoying and somewhat hostile interactions with others in the course of a lifetime. We might expect that unlawful "self defense" gun uses will outnumber the legitimate and socially beneficial ones.

Trained police officers are often inadequately prepared to handle ambiguous but potentially dangerous situations. Heavy stress, confusion, and fear are inherent in most possible shooting situations. Heart rates skyrocket, and it is difficult to think clearly and to act deliberately. Not surprisingly, even the police make serious mistakes in their firearm use. Individuals without training or experience can be expected to do much worse.

Our findings have various limitations. Our results are based on self reports of past events, with the potential of recall bias. The surveys under-sampled poor people who may have more hostile conflicts with firearms than their richer counterparts. The key questions from the two surveys, though very similar, were not identical, and neither survey sampled anyone under age 18. In addition, we have detailed information only on the most recent self defense and criminal gun incidents; to the extent that the most recent incident is not typical of all the incidents experienced by the respondent, our findings may not be representative.

Only five judges, from three states, assessed the self defense gun incidents from the surveys; 
they were a convenience rather than a random sample, and the sample is too small to be confident of the stability of the aggregate ratings we report here.

Despite these limitations, our surveys provide evidence about gun uses in American society that has not been available before. Our results indicate that gun use against adults to threaten and intimidate is far more common than self defense gun use by them, and that most self reported self defense gun uses are probably illegal, and may be against the interests of society.

This research was supported in part by the grants from the Centers for Disease Control and Prevention, the National Institute of Justice, the Open Society Institute, and the Joyce Foundation.

1 Annest JL, Mercy JA, Gibson DR, et al. National estimates of nonfatal firearm-related injuries. $\mathscr{f} A M A$ 1995;273:1749-54

2 Hemenway D, Azrael D. The relative frequency of offensive and defensive gun uses: results from a national survey. Violence and Victims (in press)

3 Skogan W. The National Crime Survey redesign. Public Opinion Quarterly 1990;54:256-72.

4 Cantor D. Substantive implications of longitudinal design features: the National Crime Victimization Survey as a case study. In: Kasprzyk D, Duncan G, Kalton G, et al, eds. Panel surveys. New York: John Wiley, 1989.

5 National Archives of Criminal Justice Data. National Crime Victimization Survey: 1986-1991, 1992-1995. http: Ilwww.icpsr.umich.edu:80/NACJD.

6 McDowall DB, Wiersema B. The incidence of civilian defensive firearm use by US crime victims. Am f Public Health 1994;84:1982-5.
7 Kleck G. Targeting guns: firearms and their control. New York: Aldine de Gruyter, 1997.

8 Hemenway D. Survey research and self-defense gun use: an explanation of extreme overestimates. Fournal of Criminal Law and Criminology 1997;87:1430-45.

9 Hemenway D. The myth of millions of annual self-defense gun uses: a case study of survey overestimates of rare events. Chance 1997;10:6-10

10 Cook PJ, Ludwig J, Hemenway D. The gun debate's new mythical number: How many defensive uses per year? fournal of Policy Analysis and Management 1997;16:463-9.

11 Cook PJ, Ludwig J. Defensive gun uses: new evidence from a national survey. Fournal of Quantitative Criminology 1998; 14:111-31.

12 Kleck G, Gertz M. Armed resistance to crime: the prevalence and nature of self-defense with a gun. Fournal of Criminal Law and Criminology 1995;273:1749-54.

13 Azrael D, Hemenway D. "In the safety of your own home". Results from a national survey on gun use at home. Soc Sci Med 2000;50:285-91.

14 Wright JD, Rossi PH, Daly K. Under the gun: weapons, crime and violence in America. Hawthrone, NY: Aldine Publishing Company, 1983.

15 Krosnick JA. Survey research. Anпu Rev Psychol 1999;50: 537-67.

16 DeMaio TJ. Social desirability and survey measurement: a review. In: Turner CF, Martin E, eds. Surveying subjective phenomena. New York: Russell Sage, 1984.

17 Gosling SD, John OP, Craik KH, et al. Do people know how they behave? Self-reported act frequencies compared with on-line coding by observers. F Pers Soc Psychol 1998;74: 1337-49.

18 John OP, Robins RW. Accuracy and bias in self-perception: individual differences in self-enhancement and the role of narcissism. F Pers Soc Psychol 1994;66:206-19.

19 Smith TW. Discrepancies between men and women in reporting number of sexual partners: a summary from four countries. Soc Biol 1992;39:203-11.

20 DelPrete LR, Caldwell M, English C, et al. Self-reported and measured weights and heights of participants in community-based weight loss programs. F Am Diet Assoc 1992;92:1483-6.

\section{From the journals}

A report in $\mathcal{F} A M A$ shows that the risk of death in cars driven by 16 and 17 year olds is related to the number of passengers. Using data from various national sources the authors found that when compared with drivers of the same age who had no passengers, the relative risk of 16 year old drivers' deaths per 10 million trips was 39\% higher for those with one passenger, $86 \%$ higher for those with two, and nearly three times higher for those with three or more passengers. Similar patterns were found for 17 year old drivers. Perhaps not surprisingly, driver crashes were greater when the passengers were male and under 30 and the death rates for teen drivers were substantially increased late at night. The authors note that a previous survey of high school drivers found that dangerous driving behaviors were strongly associated with the presence of peers. They conclude that the results support the need for graduated driver's licensing system for teens. Such a system is in place in 24 states. An accompanying editorial by Robert Foss states "This is clear and convincing evidence that state [graduated driver's licensing] systems should include passenger restrictions during the initial stages of driver licensing" ( $(A M A 2000$ (March), Li-Hui Chen and colleagues).

Many papers in our most formidable rival, Accident Analysis and Prevention, are noteworthy. In the January 2000 issue (vol 32) one by Gregersen et al reports on the beneficial effects of a 16 years age limit for learner drivers in Sweden (p 25-36) and another, by Elvik, describes the relevant costs and benefits of road safety measures for pedestrians and drivers ( $\mathrm{p} 37-46)$, There is also an exploration of the barriers to bicycle helmet use in 12 and 13 year olds by Loubeau (p 111-16). The entire March 2000 issue is devoted to whiplash and most of the papers are quite technical, mainly of interest to engineers. In the May issue the theme was domestic and personal injury. It includes important papers by Marsh and Kendrick on near miss and minor injuries; one on burn injuries in the Netherlands (Hertog et al); another on personal watercraft injuries (Jones). Also included is a report by Macarthur et al on playground falls and a meta-analysis of studies linking smoking to injury fatalities by Leistikow et al.

A report based on data from the National Electronic Injury Surveillance System in the US notes that injuries at fast food restaurants account for more than one quarter of the occupational injuries among 15-17 year olds in the US. This makes this the largest single source of work related injuries in this age group. One of the most important solutions proposed is better training, along with proper supervision and safety practices (F Occup Environ Med 1999; 41:1146-53). 